\title{
A INFLUÊNCIA DA DECISÃO SANEADORA NA CONCRETIZAÇÃO DO PROCESSO CIVIL DEMOCRÁTICO
}

\section{INFLUENCE OF THE HEALING DECISION ON THE IMPLEMENTATION OF THE DEMOCRATIC CIVIL PROCESS}

\author{
Hagnes Pedreira ${ }^{1}$ \\ Hélvia Túlia Sandes Pedreira ${ }^{2}$
}

\section{RESUMO}

O CPC/15 foi gestado com o intuito de atender os anseios progressistas da Carta Magna de 1988, esse reflexo democrático pode ser sentido na Fase de Saneamento e Organização do Processo, que foi reformulada para estar em sintonia com os princípios constitucionais. $O$ presente trabalho se propõe a analisar quais os mecanismos que a decisão saneadora se utiliza para que, assim, possa influenciar na concretização do processo civil democrático. Visando atender o objetivo da pesquisa, é imperioso estudar detalhadamente os incisos e parágrafos do artigo 357 do Código de Processo Civil de 2015; analisar a evolução histórica da atividade saneadora, compreendendo, aqui, o CPC/39, CPC/73 e o atual CPC/15; e, também, abordar sobre o conteúdo, as espécies e a estabilidade da decisão de saneamento e organização do processo. A pesquisa em questão contribuir para as áreas de direito processual civil e direito constitucional.

PALAVRAS-CHAVE: Decisão saneadora; Fase de saneamento; Processo democrático.

\section{ABSTRACT}

The CPC/15 was designed to meet the progressive aspirations of the 1988 Magna Carta, these democratic reflexes can be felt in the Sanitation and Process Organization Phase, which was reformulated to be in line with constitutional principles. This paper proposes to analyze the mechanisms used by the remedial decision to influence the implementation of the democratic civil process. In order to meet the research objective, it is imperative to study in detail the sections and paragraphs of article 357 of the 2015 Code of Civil Procedure; analyze the historical evolution of the sanitation activity,

\footnotetext{
1 Bacherela em Direito pela Universidade Federal do Tocantins. Email: hagnespedreira@gmail.com. ORCID https://orcid.org/0000-0003-2222-0023.

${ }_{2}^{2}$ Mestre em Prestação Jurisdiconal e Direitos Humanos pela Universidade Federal do Tocantins e Escola Superior de Magistratura Tocantinense - ESMAT. Pós-graduada em Direito do Trabalho e Processo do Trabalho pela Universidade Federal do Tocantins. Pós-graduada em Processo Civil pela UNITINS. Juíza de Direito no Estado do Tocantins. Professora de Processo Civil na Universidade Federal do Tocantins. Email: tuliasandes@gmail.com. ORCID https://orcid.org/0000-0002-1080-4868.
} 
including $\mathrm{CPC} / 39, \mathrm{CPC} / 73$ and the current $\mathrm{CPC} / 15$; and also address the content, species and stability of the sanitation decision and process organization. The research in question contribute to the areas of civil procedural law and constitutional law.

KEYWORDS: Healing decision; Sanitation phase; Democratic process.

\section{INTRODUÇÃO}

Com o advento da Constituição da República de 1988, houve a necessidade de modernizar o sistema processual para sustentar um ambiente mais progressista e em sintonia com as garantias asseguradas pela nova Carta Constitucional.

O atual Código de Processo Civil, concebido em um ambiente democrático, reformou instrumentos processuais para atender aos anseios do Estado Democrático de Direito. Os influxos democráticos podem ser sentidos na fase de saneamento e organização do processo, que foi reformulada com o intuito de atender os princípios constitucionais, assumindo uma roupagem cada vez mais dialógica. Essa fase tem como produto a decisão saneadora, que visa resolver eventuais vícios que ainda persistam, delimitar questões de fato e de direito, definir a distribuição do ônus probante e designar, se necessário, audiência de instrução e julgamento. No atual cenário do país, estudar os instrumentos que visam concretizar os anseios democráticos, assume extrema relevância, compreendendo, assim, o quão eles são essenciais à sociedade na efetivação de direitos ao harmonizar o sistema processual com a Carta Constitucional de 1988.

Visualizar o processo civil de acordo com o CPC/15 possibilita contemplar os inúmeros mecanismos que ele adota para que o processo seja construído em um ambiente cada vez mais contemporâneo e progressista. Portanto, o artigo em questão visa abordar como os princípios constitucionais inspiram a decisão saneadora e como ela, após ser proferida pelo juiz, será utilizada como mecanismo democratizador.

Ao responder à pergunta norteadora do trabalho ("Como a decisão saneadora pode ser instrumento de democratização no processo? "), a pesquisa busca contribuir para as áreas de direito processual civil e direito constitucional, sendo direcionada pelo método dedutivo, partindo de argumentos gerais para particulares, com perspectiva 
básica estratégica e abordagem qualitativa. $\mathrm{O}$ artigo, com vista a alcançar o objetivo pretendido, apresenta caráter descritivo ao analisar a influência da decisão saneadora na concretização do processo civil democrático.

Sendo assim, elaborou-se uma dissertação estruturada em quatro capítulos: o primeiro aborda a evolução histórica da atividade saneadora, mencionando o CPC/39, $\mathrm{CPC} / 73$ e $\mathrm{o}$ atual $\mathrm{CPC} / 15$; o segundo trata dos principais aspectos da decisão saneadora no CPC de 2015, incluindo o seu conteúdo (incisos I a $\vee$ do art. 357), as suas espécies $\left(\S 1^{\circ}\right.$ a $\S 3^{\circ}$ do art. 357$)$ e o instituto da estabilidade $\left(\S 1^{\circ}\right.$ do art. 357$)$, sendo de extrema relevância o estudo do artigo 357; o terceiro analisa a decisão saneadora como instrumento democratizador; e, por fim, a conclusão.

\section{A ESSÊNCIA DO SANEAMENTO AO LONGO DA HISTÓRIA PROCESSUAL}

\section{$2.10 \mathrm{CPC} / 39$ e o saneamento}

O despacho saneador foi introduzido no direito brasileiro através do Código de Processo Civil de 1939, tendo como influência o direito português. O CPC em questão tinha como objetivo a celeridade e oralidade, buscando deixar para trás o formalismo no processo.

Com o advento do $\mathrm{CPC} / 39$, a matéria processual, que nele estava contida, passou a vigorar para todo o país. Visto que, a Constituição Federal de 1934 atribuiu competência à União para legislar sobre direito processual. Antes disso, cada estado ficava responsável em criar suas próprias normas processuais.

O despacho saneador no CPC/39 permitia ao juiz a correção de irregularidades identificadas no processo e, também, autorizava a prática de certas providências saneadoras. Nesse momento do processo civil, o magistrado se limitava a decidir questões que não tratavam do mérito. In verbis:

Art. 294. No despacho saneador, o juiz:

I - decidirá sobre a legitimidade das partes e de sua representação, ordenando, quando for o caso, a citação dos litisconsortes necessários e do órgão do Ministério Público;

II - mandará ouvir o autor, dentro em três dias, permitindo-lhe que junte prova contrária, quando na contestação, reconhecido o fato em que se fundou, outro se lhe opuser, extintivo do pedido; 
III - examinará se concorre o requisito do legítimo interesse econômico ou moral;

IV - pronunciará as nulidades insanáveis, ou mandará, suprir as sanáveis bem como as irregularidades;

V - determinará, ex-officio ou a requerimento das partes, exames, vistorias e outras quaisquer diligências, na forma do art. 295, ordenando que os interessados se louvem dentro de 24 horas em peritos, caso já não haja feito, e indicando o terceiro desempatador, como prescreve o art. 129.

Parágrafo único. As providências referidas nos ns. I e II serão determinadas nos três primeiros dias do prazo a que se refere 0 artigo anterior. (BRASIL, 1939).

Segundo Alcides de Mendonça Lima (1990, apud PAVONI, 2018, p.19), o CPC de 1939:

[...] causou verdadeira "revolução" nos meios forenses em confronto com os diplomas regionais, elaborados ao longo de 1905 (Pará, sem o nome de Código, termo usado, pela primeira vez, no do Rio Grande do Sul, de 1908) até 1930 (o de São Paulo, o último dos chamados grandes Estados). De certa maneira, esses Códigos locais (como permitia a Constituição Federal de 1891, num excesso de federalismo) remontavam ao vestuto Regulamento n. 737, de 1850, que, por sua vez, ainda mantinha vínculos estreitos com as Ordenações Filipinas do século XVII. A cientificidade e a modernização do processo deixavam de refletir-se no âmbito regional, embora já introduzidas em Códigos europeus.

Ainda de acordo com as lições de Mendonça Lima (1989, p. 60, apud PEDRON; COSTA, 2017, p. 8), "o inédito despacho poderia não se exteriorizar em um só ato, mas, sim, em vários, em momentos até bem distantes um do outro, cronologicamente, [...]". Para ele, o despacho saneador não se verifica como sendo um único ato do juiz e, sim, vários atos saneadores ao longo do processo.

Em opinião diversa, Alvim (1970) defende a ideia de que o despacho saneador é um só, ocorrendo em um momento específico, não sendo, assim, uma decisão fragmentada.

Nos moldes do CPC de 1939, o despacho saneador era proferido pelo juiz em gabinete, de forma escrita e sem a participação das partes. 


\section{$2.20 \mathrm{CPC} / 73$ e o saneamento}

O Código de Processo Civil de 1973 ficou conhecido como Código de Buzaid, devido ao professor Alfredo Buzaid que elaborou seu anteprojeto.

Com o advento do CPC/73, houve o acréscimo do Capítulo IV intitulado "Das Providências Preliminares". Nessa fase, o juiz já analisava os pressupostos processuais e condições da ação. Ou seja, antes mesmo da decisão saneadora, o juiz já praticava atividades de saneamento.

Um interessante apontamento feito por Moreira (2012) é que essa fase irá se encerrar com a decisão saneadora, diferentemente do CPC/39 que abordava a nomenclatura "despacho saneador". Essa alteração é verificada no art. 338 do CPC/73, que foi alterado pela Lei n. 11.280 .

Outra novidade que pode ser observada com a introdução deste Código no ordenamento jurídico brasileiro é a possibilidade da resolução do mérito após as "Providências Preliminares". Afinal, após essa fase, tem-se o "Julgamento Conforme o Estado do Processo", em que poderia ensejar três pronunciamentos judiciais: extinguir o processo com e sem resolução de mérito (de acordo com os arts. 267 e 269); julgar antecipadamente o mérito; e o despacho saneador (art. 330).

Percebe-se que, o saneamento em si irá ocorrer na fase "Das Providências Preliminares", onde deverão ser analisados todos os pressupostos processuais. Caso não seja a hipótese de extinção do processo ou julgamento antecipado, o juiz irá proferir a decisão saneadora, que contém claro conteúdo declaratório. Afinal, o processo já foi saneado anteriormente. Diferentemente do despacho saneador do CPC de 1939, uma vez que, era nele que ocorria a atividade saneadora.

Segundo Figueira Jr. (2001), "quando os sujeitos da relação processual adentram na fase chamada de saneamento, o processo já se encontra saneado".

Pontes de Miranda (1974, apud PAVONI, 2018, p. 32) abordou sobre as mudanças trazidas pelo CPC de 1973 ao despacho saneador:

Deve-se ter todo o cuidado em se falar, a partir da incidência do Código de 1973, de "despacho saneador", como se fosse o mesmo conteúdo que tinha o direito anterior. [...] No direito anterior, o despacho saneador era ato de saneamento. Passou a ser ato declarativo da sanação. Não 
mais é em despacho saneador que se determinam as providências preliminares. No Código de 1973, supõe-se que tudo já esteja saneado, para que então se faça tal ato judicial, com a sua explícita declaratividade.

Superada a fase do julgamento conforme o estado do processo, sem que seja o caso de extinção ou julgamento antecipado da lide, o art. 331 do CPC de 1973 trouxe a "Audiência Preliminar", com redação dada pela Lei n. 10.444 de 2002.

Essa audiência só era designada quando o processo tinha como objeto direito disponível, tendo como finalidade a conciliação das partes. Caso não ocorresse a conciliação, o $\S 2^{\circ}$ aduz que deveriam ser fixados os pontos controvertidos, decidiam as questões processuais pendentes, determinava as provas que deveriam ser produzidas e designava audiência de instrução e julgamento, caso necessário.

Observa-se que, nas causas em que aceitavam transação, as partes participavam da produção do despacho saneador. Porém, quando se tratava de direitos indisponíveis, afastava-se a audiência e o juiz proferia a decisão saneadora em gabinete, sem a participação das partes.

Ou seja, as partes cooperavam na produção do despacho saneador apenas nos casos de direitos disponíveis, porque havia a designação da audiência preliminar que tinha como condão a conciliação.

\section{$2.30 \mathrm{CPC} / 15$ e o saneamento}

O CPC de 2015 buscou atender os anseios da Constituição Federal de 1988, afinal, surge à necessidade de criar mecanismos adequados à efetivação das garantias constitucionais, de modo a concretizar os ideais do Estado Democrático de Direito.

De acordo com a Exposição de Motivos do CPC atual:

Sem prejuízo da manutenção e do aperfeiçoamento dos institutos introduzidos no sistema pelas reformas ocorridas nos anos de 1992 até hoje, criou-se um Código novo, que não significa, todavia, uma ruptura com o passado, mas um passo à frente. Assim, além de conservados os institutos cujos resultados foram positivos, incluíram-se no sistema outros tantos que visam a atribuir-lhe alto grau de eficiência. (BRASIL, 2015). 
Cooperação das partes e do magistrado, contraditório e ampla defesa, razoável duração do processo, e efetiva tutela jurisdicional são princípios basilares do Código atual, que visam democratizar o processo civil. Consequentemente refletem na fase de saneamento, que é a essência do presente estudo.

Assim como no CPC de 1973, há a possibilidade de três pronunciamentos judiciais no "Julgamento Conforme o Estado do Processo". Extinguir o processo de acordo com os arts. 485 e 487, II e III, do CPC/15; julgar antecipadamente o mérito; ou proferir decisão de saneamento.

O art. 354 do CPC prevê duas alternativas ao juiz, ambos levando a extinção do processo. A análise do artigo em questão remete ao estudo dos arts. 485 e 487, II e III.

$\mathrm{O}$ art. 485 elenca alguns incisos que dizem respeito à extinção do processo sem resolver o mérito como, por exemplo, reconhecer a ocorrência de perempção, litispendência ou coisa julgada. Já no art. 487, II e III, aborda-se a extinção do processo mediante resolução do mérito, quando houver prescrição ou decadência e homologação de reconhecimento jurídico do pedido, de transação e de renúncia.

O segundo pronunciamento judicial diz respeito ao julgamento antecipado do mérito. Segundo Neves (2018), o processo de conhecimento pode ser dividido em quatro fases - postulatória, saneadora, instrutória e decisória. O julgamento antecipado se justifica pela prescindibilidade de se realizar a fase probatória, gerando, assim, um vácuo entre a fase de saneamento e a decisão do juiz. Não sendo necessário passar pela instrução, nas hipóteses elencadas pelo art. 355 do CPC, antecipa-se a fase decisória.

O CPC de 2015 inovou ao prever o julgamento antecipado parcial de mérito. $O$ art. 356 aduz que essa hipótese ocorrerá quando um ou mais dos pedidos formulados se mostrarem incontroversos ou quando estiverem em condição de imediato julgamento.

Caso o magistrado entenda que não cabe nenhuma das hipóteses acima elencadas, o processo deverá prosseguir, tendo como continuidade a fase processual intitulada "Do Saneamento e da Organização do Processo" (art. 357), que prepara a relação processual para a fase instrutória. O resultado dessa fase é a decisão saneadora, que tem como finalidade a resolução de questões processuais pendentes; 
delimitação das questões de fato e de direito; especificação dos meios de provas necessários; definição da distribuição do ônus da prova; e, se necessário, designação da audiência de instrução e julgamento. Ou seja, além de sanar eventuais vícios, ela visa à organização do processo, em uma espécie de roteiro, para a atividade instrutória. Possibilitando que o magistrado realize o exercício de cognição de maneira mais ampla e sistemática. Percebe-se uma íntima relação entre a cognição judicial e a atividade saneadora no processo civil.

Pelo exposto, pode-se afirmar que o art. 357 do CPC de 2015 veio com o propósito de modernizar e reorganizar a fase saneadora. Os incisos e parágrafos deste artigo trazem novos institutos jurídicos ao ordenamento processual civil que serão abordados adiante: estabilidade da decisão saneadora; pedido de esclarecimento ou ajustes; e o saneamento cooperativo em causas que apresentam complexidade.

Além das alterações com relação aos mecanismos que buscam democratizar o processo civil, o CPC de 2015 inovou ao não trazer, dentre os atos a serem praticados na fase de saneamento, a tentativa de autocomposição. Porém, apesar de não ter a previsão no art. 357, não há vedação para que o magistrado tente realizar conciliação ou mediação nesse momento processual.

Para Neves (2018), desvincular o saneamento da tentativa de solução consensual foi uma alteração correta e interessante, visto que a prática demonstra que essa confusão não levava a bons resultados.

\section{OS PRINCIPAIS ASPECTOS DA DECISÃO SANEADORA}

\subsection{O conteúdo e as espécies da decisão saneadora}

Os incisos do art. 357 trazem os tópicos que devem ser abordados pela decisão saneadora. In verbis:

Art. 357. Não ocorrendo nenhuma das hipóteses deste Capítulo, deverá o juiz, em decisão de saneamento e de organização do processo:

I - resolver as questões processuais pendentes, se houver;

II - delimitar as questões de fato sobre as quais recairá a atividade probatória, especificando os meios de prova admitidos; 
III - definir a distribuição do ônus da prova, observado o art. 373;

IV - delimitar as questões de direito relevantes para a decisão do mérito;

V - designar, se necessário, audiência de instrução e julgamento. (BRASIL, 2015).

O inciso l afirma que a decisão de saneamento e organização do processo deverá resolver, se houver, as questões processuais pendentes. Essas questões dizem respeito aos pressupostos processuais que são, basicamente, matérias preliminares, essencialmente ligadas às formalidades do processo e, também, dizem respeito às condições da ação, estas demandam uma análise da relação jurídica de direito material para verificar se há interesse de agir e legitimidade.

Adotando o posicionamento de Neves (2018), os pressupostos processuais dividem-se em pressupostos subjetivos (investidura, imparcialidade, capacidade de direito, de fato e postulatória) e objetivos, estes se subdividem em extrínsecos (coisa julgada, litispendência, perempção, transação e convenção de arbitragem) e intrínsecos (demanda, petição inicial apta, citação válida e regularidade formal).

Portanto, caso ainda persista alguma irregularidade formal, o magistrado irá sanar esses vícios na decisão de saneamento, para que, assim, o processo esteja formalmente apto para prosseguir. Em sentido contrário, caso não haja nenhuma irregularidade, o juiz irá declarar que não contém vícios no processo, estando preparado para sua regular tramitação.

Já nos termos do inciso II, o legislador aponta para a necessidade de delimitar as questões de fato que serão discutidas, portanto, fixam-se as questões controvertidas da matéria em busca do aperfeiçoamento da próxima fase processual, a instrução.

A atividade probatória irá recair exatamente sobre os pontos controversos que foram fixados. Afinal, é de grande importância tanto para as partes quanto para o juiz a exata delimitação do objeto da fase instrutória para que não haja a produção de provas em relação a fatos incontroversos ou provas de fatos que não interessam ao convencimento do julgador.

Superada a fixação dos pontos controvertidos da matéria, haverá a definição de quais meios de provas serão utilizados para cada questão de fato elencada pelas partes. Aqui, o juiz irá definir de que forma cada prova será produzida, deferindo ou indeferindo meios de prova requeridos pelas partes e, também, poderá indicar algum 
meio probatório que ele achar conveniente para a resolução eficaz da matéria. Portanto, resta fixado o que deve ser provado e qual o meio que será utilizada para provar.

Outra novidade trazida pela CPC de 2015 e que consta no inciso III, é a distribuição do ônus da prova como sendo um dos tópicos da decisão de saneamento. $\mathrm{O}$ art. 373 trata sobre $\mathrm{o}$ instituto em questão e aduz sobre a necessidade do contraditório na distribuição do ônus probatório, portanto, quando o juiz atribuir o ônus da prova de maneira diversa, deverá ser feita em decisão fundamentada e com a participação das partes, para que elas não sejam surpreendidas no momento da instrução. Sendo assim, a distribuição do ônus probante ocorrerá em um momento específico no processo, anterior ao início da fase instrutória, ou seja, na fase saneadora.

O inciso IV prevê a delimitação das questões de direito que são importantes para a decisão de mérito, afinal, elas serão a base legal para o convencimento do magistrado. Essa definição visa indicar para as partes as questões de direito que são essenciais para a cognição judicial, evitando discussões jurídicas em vão. Para Didier Jr. (2015), essa regra concretiza o art. 10 do CPC, por impor ao órgão jurisdicional o dever de consultar as partes sobre qualquer questão relevante para solucionar a causa, inclusive as questões jurídicas.

Por fim, o inciso $\mathrm{V}$ aduz que, quando necessário, será designada audiência de instrução e julgamento, onde as partes irão comparecer para contribuírem no trâmite processual. É perfeitamente possível que o processo termine sem a ocorrência da audiência em questão, em casos que não há a necessidade de se produzirem provas orais. Como, por exemplo, quando o processo já está apto para o julgamento apenas com as provas documentais que foram colhidas.

Após o art. 357 informar, em seus cinco incisos, qual o conteúdo que deve estar presente na decisão interlocutória em questão, ele traz em seus parágrafos três espécies de decisão saneadora, que foram construídas utilizando-se procedimentos diferentes, todavia, todas possuem o mesmo fim e estão pautadas no princípio da cooperação, norteador do Código de Processo Civil atual (art 6 do CPC/15). 
Em seu $\S 1^{\circ}$, a decisão saneadora é proferida pelo juiz em gabinete, sem a participação das partes. Nesse caso, elas terão 5 (cinco) dias, após a decisão, para pedirem esclarecimentos ou solicitarem ajustes.

No $\S 2^{\circ}$, há a possibilidade das partes praticarem um verdadeiro negócio jurídico processual, delimitando, consensualmente, as questões de fato e de direito e os meios de prova, após, o juiz poderá homologar ou não o negócio jurídico, que deverá respeitar todos os requisitos do art. 190 do CPC/15. Caso o juiz homologue, tanto ele quanto as partes estarão vinculados.

Por fim, o $\S 3^{\circ}$ trata da audiência de saneamento cooperativa, que ocorrerá quando o juiz entender que a causa apresenta certa complexidade fática e jurídica. Sendo assim, a elaboração da decisão saneadora será feita com a participação das partes.

Medina (2017) aborda sobre os três procedimentos que podem ser utilizados na obtenção da decisão saneadora: i) por iniciativa do juiz, possibilitando às partes pedir esclarecimentos ou solicitar ajustes $\left(\S 1^{\circ}\right)$; ii) através do negócio jurídico processual, resultando na vinculação de todos os sujeitos, caso o juiz homologue $\left(\S 2^{\circ}\right)$; iii) em audiência de saneamento e organização do processo, caso o magistrado entenda que há questões de fato e/ou de direito complexas $\left(\S^{\circ}\right)$.

\subsection{Os efeitos da estabilidade}

$\mathrm{O} \S 1^{\circ}$ do art. 357 afirma que, passados os 5 (cinco) dias sem que haja pedido de esclarecimento ou ajuste, a decisão torna-se estável.

Esse pedido é considerado um sucedâneo recursal, não podendo ser confundido com embargos de declaração, afinal, não é necessário que haja contradição, omissão, obscuridade ou erro material (requisitos indispensáveis para a propositura do recurso citado). Outro apontamento importante é que, apesar da estabilidade ser mencionada apenas no $\S 1^{\circ}$, ela recairá em todas as espécies de decisão saneadora: a proferida em gabinete, a que homologa o negócio jurídico processual e a que foi proferida em audiência de saneamento cooperativo. 
A estabilidade gera a preclusão que é a impossibilidade de rediscutir, naquela relação processual, certas questões que já foram decididas pelo juiz de primeiro grau e não foram impugnadas pelo recurso adequado, bem como a impossibilidade de praticar certo ato processual que deveria ter sido efetuado no momento oportuno, mas não o foi. A preclusão vincula tanto as partes quanto o órgão jurisdicional que proferiu a decisão saneadora. De acordo com Didier Jr. (2015), é essencial que a decisão de saneamento e organização do processo se submeta à preclusão como mecanismo para evitar retrocessos processuais.

O termo "estabilidade" é uma novidade do $\mathrm{CPC} / 15$, mas a aplicação da preclusão no saneador é estudada desde o CPC de 1939. Nas lições de Miranda (1974, apud PAVONI, 2018, p. 32), caso as partes e o juiz não se pronunciassem sobre as matérias do art. 294 do CPC/39, incidiria a preclusão.

$\mathrm{Na}$ visão de Moreira (2012), durante a vigência do CPC/73, a preclusão recaia na decisão de saneamento: i) em relação a todas as questões decididas pelo juiz, ressalvada a possibilidade de realizar prova que havia sido indeferida, mas que se verificou necessária para a instrução; ii) das questões que não foram decididas, cuja solução cabia na decisão de saneamento, exceto àquelas que podem ser resolvidas posteriormente (questões de ordem pública) como, por exemplo, a incompetência absoluta.

Moreira (2012) também assevera que a eficácia preclusiva da decisão de saneamento opera desde o momento em que esta se torna irrecorrível, seja pelo decurso in albis do prazo recursal ou por qualquer outro motivo. Em relação a esse tema, oportuno salientar que o $\mathrm{CPC} / 73$ tinha o agravo como o recurso cabível para todas as decisões interlocutórias, sendo assim, para atacar a decisão de saneamento, a parte precisava interpor o agravo no prazo de dez dias, de acordo com o art. 522 do $\mathrm{CPC} / 73$, diferentemente do $\mathrm{CPC} / 15$ em que traz um rol taxativo das matérias que admitem a interposição do recurso de agravo de instrumento (art. 1.015).

Atualmente, no $\mathrm{CPC} / 15$, ainda se discute sobre a extensão da preclusão que incide na decisão saneadora. Em posição minoritária, Didier Jr. (2015) entende que se a decisão de saneamento reconhece os requisitos de admissibilidade do processo, 
opera-se a preclusão, ressalvados os fatos supervenientes que impõem uma nova decisão.

Porém, a doutrina dominante adota posição mais flexível. Entende-se que a preclusão incidirá apenas nas questões de fato e direito, nos meios de prova especificados e na distribuição do ônus probante, caso a parte se mantenha inerte e não utilize recurso adequado para impugnar a decisão. As questões de ordem pública (art. 357, I) não precluem, podendo ser conhecidas até o trânsito em julgado.

A decisão saneadora pode ser impugnada em preliminar de apelação $\left(\S 1^{\circ}\right.$ do art. 1.009), com exceção das hipóteses que permitam a impugnação imediata por agravo de instrumento, como no caso de redistribuição do ônus da prova, nos termos do art. 373, $\S 1^{\circ}$ (art. 1.015, XI).

Passos (2004, apud DIDIER JR., 2015, p. 700) asseverou que, se a decisão é recorrível, não se pode cogitar, no direito brasileiro, o reexame de questões que já foram decididas e não foram impugnadas. Portanto, se a parte não agrava ou apela, haverá preclusão e o tribunal não poderá analisar a respeito dessas matérias, vinculando as partes e o juiz.

Importante ressaltar que a preclusão não se opera em relação aos fatos supervenientes, sendo assim, quando o juiz profere decisão saneadora, e caso ocorra um fato superveniente a ela, será necessária uma nova decisão.

Também cabe ressaltar que a preclusão não deve prosperar em decisões implícitas em decorrência do princípio da motivação das decisões judiciais, afinal, inviabilizaria a sua impugnação pelas partes (art. 93, IX, CF/88; arts. 11 e 489, $\S 1^{\circ}$, CPC).

\section{A DECISÃO SANEADORA COMO INSTRUMENTO DEMOCRATIZADOR}

O juiz, ao longo da relação processual, adota várias providências que têm como finalidade gerenciar o processo. Segundo Cahali (2012), utiliza-se um conjunto de medidas que buscam solucionar a demanda da forma mais adequada, buscando obter o máximo de rendimento, com menor custo e duração. 
O legislador, atento à necessidade de gerenciar o processo da maneira mais satisfatória possível, concentrou na fase saneadora, os atos processuais que tenham como objetivo sanar eventuais vícios e organizar o processo em si, criando uma espécie de roteiro que irá contribuir para a adequada cognição judicial.

A decisão de saneamento e organização do processo, fruto da atividade saneadora, possui inúmeros contornos progressistas, estando em sintonia com o propósito do CPC/15. Sendo assim, é imperioso analisar a influência que essa decisão desempenha na concretização do processo democrático:

(i) Ao delimitar as questões de fato e direito, a decisão saneadora está contribuindo para que haja maior segurança jurídica no processo, visto que, o juiz só poderá embasar a decisão de mérito em fundamentos diversos dos que foram elencados na decisão de saneamento, se for dada às partes a oportunidade de se manifestar (vedação à decisão-surpresa).

(ii) Outra contribuição que pode ser analisada é que a instrução processual passa a se desenvolver de maneira mais efetiva, afinal, a decisão de saneamento e organização do processo elaborou um roteiro para ser utilizado nesse momento. Antes mesmo de iniciar a audiência de instrução e julgamento, o juiz e as partes já possuem plena consciência de quais são os fatos controvertidos, quais meios de prova devem ser utilizados, quem tem o ônus de provar o quê e quais as questões jurídicas que foram elencadas, tornando essa fase processual muito mais objetiva. Possibilitando a formação de uma sentença de mérito coesa, realista e que atenda a real necessidade da parte, sendo instrumento para obter a efetiva tutela jurisdicional.

(iii) Nas três espécies de decisão de saneamento e organização do processo é possível visualizar a notável influência do princípio da cooperação e do devido processo legal. Quando proferida em gabinete $\left(\S 1^{\circ}\right.$ do art. 357 ), as partes têm 5 (cinco) dias para pedirem esclarecimentos ou ajustes, trazendo para elas a faculdade de interferirem significativamente nessa hipótese de decisão saneadora, possibilitando um diálogo efetivo com o órgão judicial. A segunda espécie é a decisão saneadora que homologa o negócio jurídico processual, ou seja, são as partes que delimitam, consensualmente, quais são os fatos que devem ser analisados, qual o amparo legal a ser utilizado e quais os meios de prova. A terceira espécie ocorre quando o juiz verifica a necessidade 
de designar audiência em causas que apresentam complexidade em matéria de fato ou de direito, oportunizando a construção da decisão de saneamento com a cooperação das partes para que elas possam esclarecer as alegações a respeito dos fatos controversos e do direito.

(iv) Ao elaborar um roteiro processual em cooperação com as partes, a decisão de saneamento busca evitar o dispêndio de tempo em discussões desnecessárias, centralizando a atividade de cognição judicial nas questões realmente relevantes, contribuindo, assim, para a razoável duração do processo.

(v) A preclusão evita a rediscussão de questões decididas que não foram impugnadas por recurso adequado e, também, impossibilita a prática de ato processual que deveria ter sido efetuado no momento oportuno, mas não o foi. Opera-se na decisão de saneamento a preclusão, impedindo a marcha-ré processual e colaborando tanto para a razoável duração do processo quanto para a segurança jurídica. Nesse sentido, cabe citar a Apelação Cível julgada pelo Tribunal de Justiça do Rio de Janeiro em que a parte não especificou as provas que queria produzir na fase saneadora, acarretando, assim, a preclusão:

APELAÇÃO CÍVEL. AMPLA. ALEGAÇÃO DE COBRANÇAS EXCESSIVAS. PEDIDO DE PRODUÇÃO DE PROVA PERICIAL FORMULADO APÓS A DECISÃO DE SANEAMENTO DO PROCESSO. PRECLUSÃO. AUSÊNCIA DE PROVA MÍNIMA DO DIREITO ALEGADO. MANUTENÇÃO DA SENTENÇA. Lide que deve ser julgada à luz do Código de Defesa do Consumidor. O autor alegou que foi surpreendido com cobranças excessivas a partir de setembro de 2015, após um problema na rede externa. A sentença julgou os pedidos improcedentes. Em suas razões recursais, o apelante requereu a nulidade da sentença com a consequente reforma, sob o argumento de que a prova produzida pela concessionária não possibilitou alcançar a conclusão sobre o consumo exagerado. No entanto, não assiste razão ao apelante, pois, da análise atenta da instrução processual, depreende-se que ele foi devidamente intimado para especificar provas e permaneceu inerte, o que acarretou a preclusão. Precedentes do Superior Tribunal de Justiça sobre o tema. O pedido posterior à decisão saneadora se tornou extemporâneo. $O$ apelante deveria produzir lastro mínimo do direito alegado, na forma do que preconiza o artigo 373, I, do Código de Processo Civil, porém isso não ocorreu nos autos em questão. DESPROVIMENTO DO RECURSO. (TJRJ - APL: 00047748820168190008 RIO DE JANEIRO BELFORD ROXO 3 VARA CIVEL, Relator: ALCIDES DA FONSECA NETO, Data de 
Julgamento: 01/02/2018, VIGÉSIMA CÂMARA CÍVEL, Data de Publicação: 06/02/2018) (grifo nosso)

Preclusão quanto à produção probatória ocorre porque a parte deve indicar, na petição inicial ou contestação, quais as provas desejam utilizar (art. 319, VI), caso queira produzir outros meios de provas não descritos na primeira manifestação deverá mencioná-las no momento processual oportuno (fase saneadora). A não especificação acarretará preclusão. Portanto, se a parte só deseja produzir as provas que ela especificou na inicial ou na contestação, o desatendimento ao despacho de especificação de provas, na fase de saneamento, não poderá prejudicá-la, visto que já foram especificadas anteriormente. Nesse sentido, oportuno trazer a baila o seguinte julgado:

AGRAVO REGIMENTAL. AGRAVO DE INSTRUMENTO. PROVA EXPRESSAMENTE REQUERIDA NA INICIAL. INÉRCIA QUANTO AO DESPACHO DE ESPECIFICAÇÃO DAS PROVAS. JULGAMENTO DE IMPROCEDÊNCIA, JUSTAMENTE POR FALTA DE PROVAS.

1. O Código de Processo Civil indica o momento processual adequado para o pedido de produção de provas: para o autor, a petição inicial; para o réu, a contestação.

2. É lícito ao juiz determinar que as partes especifiquem as provas que pretendem produzir, depois de delimitadas as questões de fato controvertidas. Mas lhe é defeso ignorar o pedido já formulado na petição inicial, ainda que a parte não responda ao despacho de especificação.

3 . Há cerceamento de defesa quando o juiz deixa de colher as provas expressamente requeridas na petição inicial e julga improcedente 0 pedido, justamente por falta de provas. (AgRg no Ag 388.759/MG, Rel. Ministro HUMBERTO GOMES DE BARROS, TERCEIRA TURMA, julgado em 25/09/2006, DJ 16/10/2006, p. 362) (grifo nosso)

(vi) O magistrado, ao proferir a decisão saneadora, deverá atender todas as exigências assentadas nos incisos do art. 357 do CPC/15, devendo mencionar expressamente sobre a resolução das questões processuais pendentes, delimitação das questões de fato e direito, especificação dos meios de provas, definição do ônus probante e designação, se necessário, da audiência de instrução e julgamento. Importante salientar que os Tribunais têm decidido pela nulidade da sentença, por cerceamento de defesa, quando o juiz de primeiro grau não atende as exigências impostas pelo artigo em questão. Nessa linha é o seguinte precedente: 
RESPONSABILIDADE CIVIL - ACIDENTE DE TRÂNSITO - NULIDADE PROCESSUAL RECONHECIDA - CERCEAMENTO DE DEFESA CONFIGURADO - JULGAMENTO NO ESTADO - IMPOSSIBILIDADE NECESSIDADE DE PRODUÇÃO DE PROVAS ANTE A ALEGAÇÃO DE FATOS QUE DEPENDEM DE MAIOR ELUCIDAÇÃO CONSTATAÇÃO, ADEMAIS, DA NECESSIDADE DE DELIMITAÇÃO DAS QUESTÕES DE FATO SOBRE AS QUAIS DEVERÁ RECAIR A ATIVIDADE PROBATÓRIA, ESPECIFICANDO-SE OS MEIOS DE PROVA QUE SERIAM REALIZADOS - ORGANIZAÇÃO PROSPECTIVA DA FASE INSTRUTÓRIA A CARGO DO JUIZ QUE SE MOSTRA IMPRESCINDÍVEL - AUSÊNCIA DE DELIMITAÇÃO QUANTO AOS PONTOS CONTROVERTIDOS DA DEMANDA QUE OCASIONOU PREJUIIZO AOS AUTORES ANTE A NÃO ELUCIDAÇÃO DOS DANOS MATERIAIS E ESTÉTICOS POSTULADOS, TIDO COMO INDEVIDOS EXATAMENTE POR FALTA DE PROVAS - PROCESSO ANULADO, COM DETERMINAÇÃO DE REABERTURA DA FASE DE SANEAMENTO E ORGANIZAÇÃOO DO PROCESSO, A FIM DE QUE O JUÍZO A QUO PROCEDA NOS TERMOS DO ART. 357 DO CPC/2015, CUJAS DISPOSIÇÕES APLICAM-SE DESDE LOGO AOS PROCESSOS EM CURSO - ART. 1.046 DO CPC/2015." (TJSP - APL 1025578-75.2014.8.26.0577, Relator: Desembargador Edgard Rosa, 25.a Câmara de Direito Privado, Publicação: 18/3/2016.) (grifo nosso)

No julgado acima, a sentença foi declarada nula, impondo o seu retorno ao juízo de primeiro grau para reabrir a fase de saneamento e organização do processo, uma vez que não foi atendida a delimitação quanto às questões de fato, disposto no inciso II do art. 357 do CPC/15, prejudicando a atividade probatória e acarretando cerceamento de defesa.

\section{CONSIDERAÇÕES FINAIS}

A decisão de saneamento e organização do processo é utilizada como instrumento eficaz na concretização dos princípios constitucionais e, consequentemente, possibilita a formação de um processo civil democrático e progressista, contribuindo para a sociedade como um todo.

$\mathrm{Na}$ fase saneadora, cabe ao magistrado atender todas as exigências do art. 357 do CPC/15. Deixando delineadas na decisão de saneamento as questões processuais pendentes, delimitadas as questões de fato e direito, definida a distribuição do ônus probante e a designada, se necessário, a audiência de instrução e julgamento. Caso o 
magistrado venha a ser omisso em relação a uma dessas exigências, a decisão pode vir a ser anulada.

A delimitação das questões de fato e de direito relevantes para o julgamento da causa, contemplada nos incisos II e IV do art. 357, traz maior segurança jurídica; afinal, o juiz só poderá embasar a decisão de mérito em fundamentos diversos dos que foram elencados na decisão de saneamento, se for dada às partes a oportunidade de se manifestar. Percebe-se, aqui, o claro respeito ao princípio que veda a decisão-surpresa.

Ao elaborar o roteiro processual, a decisão de saneamento visa à efetiva tutela jurisdicional, possibilitando a execução de uma instrução mais objetiva e, com isso, uma decisão mais coesa e realista. Visa, também, a razoável duração do processo, evitando discussões desnecessárias e convergindo a cognição judicial nos assuntos relevantes para a resolução do feito.

O §1 ao §3 do art. 357 traz clara influência do princípio da cooperação, já que as três espécies de decisão saneadora são construídas em colaboração com as partes, possibilitando um diálogo efetivo com o órgão julgador.

Por fim, cabe relembrar que a estabilidade gera a preclusão das matérias que foram decididas $\left(\$ 1^{\circ}\right.$ do art. 357), com exceção das questões de ordem pública, impedindo a marcha-ré processual e colaborando tanto para a razoável duração do processo quanto para a segurança jurídica.

\section{REFERÊNCIAS}

ALVIM, José Manuel de Arruda. Despacho saneador. Justitia, São Paulo, v. 32, n. 69, abr.jun. 1970. Disponível em: www.revistajustitia.com.br/revistas/4a221d.pdf. Acesso em: 12 nov. 2019.

BRASIL. Lei n. 13.105, de 16 de março de 2015. Código de Processo Civil. Brasília, DF: Presidência da República, 2015. Disponível em: http://www.planalto.gov.br/ccivil_03/_ato2015-2018/2015/lei/13105.htm. Acesso em: 04 nov. 2019.

. Lei n. 1.608, de 18 de setembro de 1939. Código de Processo Civil. Brasília, DF: Presidência da República, 1939. Disponível em: http://www.planalto.gov.br/ccivil_03/Decreto-Lei/1937-1946/Del1608.htm. Acesso em: 04 nov. 2019. 
Lei n. 5.869, de 11 de janeiro de 1973. Institui o Código de Processo Civil. Brasília, DF: Presidência da República, 1973. Disponível em: http://www.planalto.gov.br/ccivil_03/LEIS/L5869impressao.htm. Acesso em: 04 nov. 2019.

CÓDIGO de processo civil e normas correlatas. Exposição de motivos da Lei n. 13.105/15. 7. ed. Brasília, DF: Senado Federal; Coordenação de Edições Técnicas, 2015. p. 25-26 Disponível em:

https://www2.senado.leg.br/bdsf/bitstream/handle/id/512422/001041135.pdf. Acesso em: 04 nov. 2019.

CAHALI, Cláudia Elisabete Schwerz. O gerenciamento do processo. 2012. $201 \mathrm{f}$. Tese (Doutorado)-Pontifícia Universidade Católica de São Paulo, São Paulo, 2012.

DIDIER JR., Fredie. Curso de direito processual civil: parte geral e processo de conhecimento. 17. ed. Salvador: JusPodivm, 2015.

FIGUEIRA JR., Joel Dias. Comentários ao Código de Processo Civil. São Paulo: Revista dos Tribunais, 2001. v. 4, Tomo II.

MEDINA, José Miguel Garcia. Novo Código de Processo Civil Comentado. 5. ed. São Paulo: Revista dos Tribunais, 2017. 643 p.

MENDONÇA LIMA, Alcides de. Do saneamento do processo. In: FABRíCIO, Adroaldo Furtado et al. (org.). Saneamento do processo: estudos em homenagem ao Prof. Galeno Lacerda. Porto Alegre: Fabris, 1989. In: PEDRON, Flávio Quinaud; COSTA, Jéssica Nayara Duarte. O Saneamento no Processo Civil como Instrumento de Efetividade da Atividade Jurisdicional. Revista de Processo, v. 274, p. 161-203, dez. 2017. p. 8. Disponível em: https://www.academia.edu/35437051/O_SANEAMENTO_NO_PROCESSO_CIVIL_CO MO_INSTRUMENTO_DE_EFETIVIDADE_DA_ATIVIDADE_JURISDICIONAL. Acesso em: 04 nov. 2019.

Do saneamento do processo. Revista de Processo, v. 60, p. 7-14, out./dez.1990. In: PAVONI, Mariana Melo. Os novos aspectos da decisão saneadora. 2018. 181 f. Dissertação (Mestrado em Direito Processual Civil)-Pontifícia Universidade Católica de São Paulo, São Paulo, 2018. p. 19. Disponível em: https://tede.pucsp.br/handle/handle/21992. Acesso em: 30 out. 2019.

MIRANDA, Pontes de. Comentários ao Código de Processo Civil. Rio de Janeiro: Forense, 1974. tomo IV. In: PAVONI, Mariana Melo. Os novos aspectos da decisão saneadora. 2018. 181 f. Dissertação (Mestrado em Direito Processual Civil)-Pontifícia Universidade Católica de São Paulo, São Paulo, 2018. p. 32. Disponível em: https://tede.pucsp.br/handle/handle/21992. Acesso em: 30 out. 2019. 
MOREIRA, José Carlos Barbosa. O novo processo civil brasileiro: exposição sistemática do procedimento. 29. ed. rev. e atual. Rio de Janeiro: Forense, 2012.

NEVES, Daniel Amorim Assumpção. Manual de direito processual civil. 10. ed. Salvador: JusPodivm, 2018. v. único.

PASSOS, José Joaquim Calmon de. Comentários ao Código de Processo Civil. 9. ed . Rio de janeiro: Forense, 2004. v. 3. In: DIDIER JR., Fredie. Curso de direito processual civil: parte geral e processo de conhecimento. 17. ed. Salvador: JusPodivm, 2015. 